Working Paper No. 263

November 2008

www.esri.ie

\title{
Comparing Poverty Indicators in an Enlarged EU
}

\author{
Christopher T. Whelan and Bertrand Maître
}

\begin{abstract}
In this paper, using the EU-SILC 2006 data-set, we seek to explore the extent to which a consideration of welfare regime and socio-economic differences in poverty levels and patterns and variation in the consequences of poverty for economic stress can assist us in making informed choices between alternative poverty indicators. Poverty in the EU is normally defined in terms of income thresholds defined at the level of each member state. However, the enlargement of the EU and the consequent widening of the gap in living standards between the richest and the poorest member states has had the consequence that a country such as Ireland perform poorly in comparison with a number of the New Member States (NMS) despite enjoying obvious advantages in terms of material living standards. Such paradoxical findings have produced a number of different but interrelated responses. The first focuses on the limitations imposed by an entirely national frame of reference. An alternative critique takes as its starting point the fact that low income is an unreliable indicator of poverty. In this paper we seek to explore the strength of both critiques by comparing the outcomes associated with measuring being 'at risk of poverty' and consistent poverty at both national and EU levels. Our analysis suggest that it is possible to develop an approach that would allow us to achieve the stated EU objective of assessing the scale of exclusion from minimally acceptable level of standards of living in individual countries while also measuring the extent to which the whole population of Europe is sharing in the benefits of high average prosperity.
\end{abstract}

Corresponding Author: Bertrand.Maitre@esri.ie

ESRI working papers represent un-refereed work-in-progress by members who are solely responsible for the content and any views expressed therein. Any comments on these papers will be welcome and should be sent to the author(s) by email. Papers may be downloaded for personal use only. 


\section{Comparing Poverty Indicators in an Enlarged EU}

\section{Introduction}

In this paper, using the EU-SILC 2006 data-set, we seek to explore the extent to which a consideration of welfare regime and socio-economic variation in poverty levels and patterns and variation in the consequences of poverty for subjectively experienced economic stress can inform our understanding of the strengths and weaknesses of alternative poverty indicators.

Poverty in the EU is normally defined in terms of income thresholds defined at the level of each member state. The 'at risk of poverty' indicator identifies those individuals falling below $60 \%$ of the national median disposable equivalent income appropriately adjusted for household composition. The conceptual foundations of this approach can be found in Townsend's (1979) definition of poverty as 'exclusion from ordinary living patterns and activities due to lack of resources'. Those falling more than a certain 'distance' below a certain nationally defined income level are understood to be excluded from a minimally acceptable way of life.

The current set of common EU-indicators of poverty and social exclusion used in the context of the Open Method of Coordination (OMC) relies heavily on such measures. The emphasis on a purely relative perspective, taking conditions in one's own country as the benchmark, has been justified by the European Commission in the following terms:

"An absolute notion is considered less relevant for the EU for two basic reasons. First the challenge for Europe is to make the whole population share the benefits of high average prosperity and not to reach basic standards of living as in developed parts of the world. Secondly, what is regarded as minimal acceptable living standards depends largely on the general level of social and economic development, which tends to vary considerably across countries (European Commission, 2004).

However, the enlargement of the EU and the consequent widening of the gap in living standards between the richest and the poorest member states has had the consequence that a country such as Ireland performs poorly in comparison with a number of the 
New Member States (NMS) despite enjoying obvious advantages in terms of material living standards. As Guio (2005a) observes, such findings have provoked concern about the ability of the current portfolio of indicators to satisfactorily reflect the situation of the New Member States and facilitate meaningful comparison between them and the 'old' Member States. Förster (2005:32) notes that the labelling of the relative income measure as 'at risk of poverty' reflects the tendency of governments to interpret it as an indicator of inequality in income distribution rather than as a measure of poverty as such.

These paradoxical findings have produced a number of different but interrelated responses. The first focuses on the limitations imposed by the entirely national frame of reference. Fahey (2007) argues for the development of an EU-wide measure alongside a nationally relative measure and recent exercises of this sort include Brandolini (2007) Kangas and Ritakallio (2007). ${ }^{\mathrm{i}}$ An alternative critique takes as its starting point the fact that a variety of studies in industrialized countries have shown that low income is an unreliable indicator of poverty in this sense, failing to identify those experiencing the forms of deprivation that one would expect to characterises those excluded from customary living patterns. ${ }^{\text {ii }}$

In this paper we seek to explore the strength of both critiques by comparing the outcomes associated with measuring being ‘at risk of poverty' and consistent poverty at both national and EU levels. By consistent poverty we mean being both below a relevant income threshold such as $60 \%$ of equivalized income and being above a specified material deprivation threshold. Such a measure has been employed in Ireland for some time ${ }^{\mathrm{iii}}$ and has recently been applied on a comparative basis by Förster (2005).

Our analysis is based on data from EU-SILC 2006 covering 26 countries. Since our purpose is to facilitate evaluation of the merits of different measures of poverty, rather than to provide a descriptive account of European poverty and deprivation patterns ${ }^{\text {iv }}$, our focus will be at the level of welfare regime. Since, our purpose is to explore the relative merits of different poverty indicators rather than provide a detailed account of welfare regime variation in the impact of socio-demographic factors, we focus on the 
interaction between welfare regime and the principal economic status of the household reference person (HRP).

As Gallie and Paugam (2000:3-4) observe, a welfare regime refers to a system of public regulation that is concerned to assure the protection of individuals and to maintain social cohesion by intervening, through both legal measures and the distribution of resources. The usefulness of a regime model may vary between welfare domains. In developing their 'employment regime' typology; they focus on the degree of benefit coverage and level of financial compensation for the unemployed and the scale of active employment policies. Bukodi and Róbert (2007) add a related concern with the strictness of employment protection legislation (EPL) comprising a set of rules governing the hiring and firing process that can be provided through labour legislation and collective bargaining arrangements. Combining these criteria with those reflected in the standard Esping-Andersen categorisation they distinguish six welfare regimes, which we employ in our subsequent analysis, as follows:

- The social democratic regime assigns the welfare state a substantial redistributive role. A high level of employment flexibility is combined with high security in the form of generous social welfare and unemployment benefits to guarantee adequate economic resources independently of market or familial reliance. We have included Sweden, Denmark, Iceland, Finland, Norway and Netherlands in this cluster. ${ }^{\mathrm{v}}$

- The corporatist regime involves less emphasis on redistribution and views welfare primarily as a mediator of group-based mutual aid and risk pooling, with rights to benefits depending on being already inserted in the labour market. Relatively strict EPL policies are aimed at protecting established inside worker and involve mainly passive labour market policies. This cluster includes Germany, Austria, Belgium, France and Luxembourg.

- The liberal regime acknowledges the primacy of the market and confines the state to a residual welfare role, social benefits typically being subject to a means test and targeted on those failing in the market. These countries exhibit 
levels of flexibility coupled with limited measures to actively sustain employment. ${ }^{\text {vi }}$ The UK and Ireland constitute this group.

- The southern European regime is distinguished by the crucial role of family support systems. Labour market policies are poorly developed and selective. The benefit system is uneven and minimalist in nature and lacks a guaranteed minimum income provision. This group comprises Cyprus, Greece, Italy, Portugal, and Spain.

- Alber et al. (2007) and Juhász (2006) note the difficulties involved in categorising the welfare regimes of post-socialist countries and the extent of variation across them, although low levels of spending on social protection and weakness of social rights are common. Bukodi and Róbert (2007) note that their has been a general increase in employment flexibility with most transition countries displaying a level of labour market flexibility significantly less than the UK but significantly greater than in southern European. Cedefop (2001) conclude that the Baltic countries, have gradually moved away from a model of regulated inclusion to one characterised by competitive regulation. Bukodi and Róbert (2007) distinguish two clusters within this overall group. The corporatist post-socialist regime comprises the central European countries, with mostly transfer oriented labour market measures and a moderate degree of employment protection.The Czech Republic, Hungary, Poland, Slovenia and Slovakia are included in this cluster.

- The post-socialist liberal cluster comprises the Baltic countries which are characterised by a more flexible labour market, with employers, particularly in the private sector, unwilling to abide by legal regulation of the market, and an absence of policies aimed at sustaining employment. Estonia, Latvia, Lithuania are included in this group.

Our purpose in analysing variation in poverty rates by welfare regime and HRP PES is to provide a basis for an evaluation of the validity of different indicators. This assessment is undertaken from a construct validity perspective in which the adequacy 
of an indicator is evaluated by considering its relationship to other key indicators in light of our prior theoretical expectations of how such a measure should behave.

Below we set our understanding of how an indicator of poverty should vary across welfare regimes and the HRP PES of the household in which the individual is located. In so doing it is necessary to take into account that poverty rates will vary across and within welfare regimes not only in relation to underlying distributional and employment regulation principles but also with respect to the level of resources available in the constituent societies.

A satisfactory measure of poverty should identify a minority in each society experiencing 'exclusion from customary living standards due to lack of resources who are excluded from customary living patterns’.

The number identified as poor will vary in line with the overall level of prosperity in the society and with the characteristics of the welfare regime but that the patterns that emerge will be significantly influenced by the poverty indicator under consideration. We anticipate low poverty rates for social-democratic regimes, somewhat higher levels for corporatist and liberal regimes, intermediate levels for the southern European cluster, significantly higher levels for the post-socialist corporatist group and the highest levels for the post-socialist liberal cluster.

We also expect systematic variation within regimes by employment status of the household reference person but that such variation will differ from one welfare regime to another. We anticipate that individuals in households where the HRP is in full-time employment will be largely insulated from poverty in the social democratic, corporatist and liberal regimes but that this will be less true in relation to the remaining clusters. Where the HRP is part-time employed we expect that poverty rates will be proportionately higher.

The social democratic regime should display the lowest poverty rates where the HRP is retired or excluded from the labour market as in case of inactivity, illness/disability and unemployment with the rate for the final group being distinctively high. We also 
expect the corporatist groups to display the next lowest rates in relation to retirement and those groups excluded from the labour market. For the remaining employment status categories we expect significantly higher rates for all these groups in the remaining regimes but with both liberal regimes exhibiting distinctively high levels in comparison with regimes enjoying comparable levels of affluence and the retired in the post-socialist corporatist cluster enjoying a particular advantage over the other groups excluded from the labour market.

We expect that within regime relativities between employees and the remaining groups would be significantly stronger in the liberal, social democratic and corporatist clusters than in the remaining regimes. In consequence, we would also expect that between regime differences in poverty risks would be greater in the employee categories than in the remaining ones and would be likely to be weakest for the unemployed.

We also expect that a valid indicator of poverty will distinguish appropriately between those experiencing subjective economic stress and all others.

\section{Data and measures}

The Eurostat User Database EU-SILC 2006 covers 26 countries, 24 EU members states (Malta not being in the survey) as well as Norway and Iceland. The household survey is made of 202,978 households which is a total of 536,993 individuals. The sample sizes across countries range from 8,598 individuals in Iceland to 54,512 in Italy. The unit of analysis is the individual.

The income measure we employ throughout this publication is the annual total household disposable income adjusted for household size using the OECD modified equivalence scale. The income reference period is the 12 months prior to date of interview.

Our analysis of deprivation focuses on a 7-item index of 'consumption deprivation' that comprises items ranging from enforced absence relating to current requirement such as food and heat to more general consumption items such as being able to afford 
a holiday, a car or a PC, as well as avoiding arrears on regular bills such as rent or utilities. Confirmatory factor analysis reveals that this dimension emerges as a distinct factor with loadings ranging from 0.889 for 'a weeks holiday away from home' to 0.565 for arrears. ${ }^{\text {vii }}$ For the 24 EU countries the Cronbach alpha is 0.72 . Relatively little variation is observed across welfare regimes with alpha ranging from 0.67 to 0.73 .

The items conform to the stipulation by Guio (2005a:2) that appropriates indicators should fulfil the following requirements:

- Reflect the lack of an ordinary living pattern common to a majority of the population in the European Union and most of its member states.

- Allow international comparisons.

- Allow comparison over time.

- Be responsive to changes in the level of living of people.

Our analysis proceeds as follows. Focusing first on 'at risk of poverty' (ARP), we produce measures at national level and for the $24 \mathrm{EU}$ countries included in the EUSILC 2006 data-set (EUARP). We then produce a number of consistent poverty measures across geographic units. These indicators are constructed by combining information on 'at risk of poverty' and consumption deprivation. The three indicators are as follows:

- A national consistent poverty (NCP) indicator. This is constructed by choosing a deprivation threshold at the national level that identifies a fraction of the population that corresponds as closely as possible to the number below the $60 \%$ of the national median equivalised income. This approach will affect national rankings only to the extent that the income and deprivation measures overlap more closely in some countries rather than others.

- The second measure is an EU consistent poverty (EUCP) measure. In this case those defined as consistently poor are both the 'at risk of poverty' using the EU threshold and above the deprivation threshold that identifies a fraction of 
the population as close as possible to that found below the corresponding income threshold.

- The final measure constructed is a mixed level consistent poverty (MLCP) indicator combining income information at the national level with information relating to consumption deprivation at the EU-level. The procedure involves identifying a fraction of the EU population as a whole that corresponds as closely as possible to the number below the EU 'at risk of poverty' line relating to $60 \%$ of the median of the equivalent income. In this case, in order to be defined as poor, an individual must be located below the national 'at risk of poverty' threshold and above the corresponding EU consumption deprivation threshold.

At national and European levels we have adopted a strictly relative approach in defining deprivation thresholds. Setting the thresholds in terms of the numbers being 'at risk of poverty' means that the numbers deprived cannot vary independently of the levels of 'at risk of poverty'. However, since one of our main objectives is to consider how the latter measures behave this has the advantage that it allows for the range of agreement between the measures to ranges from zero to one.

The measure to which this argument does not apply is the mixed consistent poverty measure which combines a national relative threshold in relation to income and a European relative threshold for deprivation derived from the corresponding income threshold. At first glance, this may appear to combine an absolute approach to deprivation material deprivation with a relative approach to income. At a particular point in time this is true. Thus for the EU-SILC 2006 data set, an individual will be defined as experiencing mixed consistent poverty if they fall below $60 \%$ of national relative income and are above the EU deprivation threshold of 0.266 on the weighted consumption deprivation index. The latter corresponds to a raw mean of 2.797 on the 7-item index. However, given the manner in which we have defined the deprivation threshold it will change as the number below the EU 'at risk of poverty line' declines or rises. 


\section{Poverty outcomes by type of indicator and welfare regime}

In Table 1 we set out the distribution of poverty levels by type of indicator and welfare regime. Where we are providing population estimates we use the grossing weight relating to population size. However, where our focus in on relationships we refrain from doing so and our analysis thus assumes that relationships are uniform within regimes. In this latter case we exclude Luxembourg because the combination of small population and the distinctive nature of the observations relating to it would distort our findings. Focusing first on the NARP rate, we can see that the lowest observed rate of 11.1 per cent is observed for the social democratic regime. This rises to 13 per cent for the corporatist regime. It then rises to 19.2 and 19.7 per cent respectively for the liberal and southern European regimes. The post-socialist corporatist rate is somewhat lower at 16.3 per cent while the highest level of 20.7 per cent is observed for the post-socialist liberal.

The foregoing pattern of results clearly does not conform to the expectations we outlined earlier. This is particularly true in relation to the comparison between the liberal and southern European regimes and the post socialist clusters where societies that we know to be significantly less affluent display poverty rates that are lower, or at least not particularly higher, than those we know to be much more favourably placed in this regard. Does shifting from a unidimensional to a multidimensional perspective produce a more plausible ranking of regimes? A consideration of the results relating to the NCP indicator shows this is not to be the case. This measure takes into account the extent of the overlap within countries between low income and high levels of material deprivation. The approach is multidimensional but remains purely relative in focusing solely on the distribution of both variables within regimes. Implementing this approach produces a substantial reduction in poverty rates ranging from a halving to a reduction to less than one third of their original level.

These finding provide unequivocal support for the argument that low income on its own provides an inadequate basis for capturing exclusion from ordinary living patterns. However, there is no evidence that variation in the strength of the relationship between income and deprivation across regime helps to account for the corresponding distribution of NARP. The overlap is weakest at 32 and 36 per cent for 
the social democratic and corporatist, it is higher at 47 per cent for the liberal regime than for the remaining regimes where the level ranges between 41 to 44 per cent. Contrary to the argument that the 'at risk of poverty' measures proves to be less effective in identifying those excluded from customary living patterns in the New Member States, it is in fact precisely in those societies where they prove to be most effective in identifying those most exposed to material deprivation. The most serious challenge to the successful application of NARP approach as a means of identifying the most excluded individuals within a country does not arise from EU enlargement as such but from the long established fact that the assumptions underlying Townsend's relative income approach cannot be sustained in the more affluent EU societies. viii

The outcome for the NCP indicator is that the social democratic and corporatist regimes continue to display the lowest poverty rates with figures of 3.4 and 4.6 per cent. They are again followed by the post-socialist corporatist group with a rate of 7.1 and the southern European with one of 8.1 per cent. The highest rates of 9.0 and 9.2 per cent respectively are observed for the liberal and post-socialist liberal regimes.

\begin{tabular}{|c|c|c|c|c|c|}
\hline & NARP & NCP & EUARP & EUCP & MCP \\
\hline & $\%$ & $\%$ & $\%$ & $\%$ & $\%$ \\
\hline Social Democratic & 11.1 & 3.4 & 6.1 & 1.8 & 3.2 \\
\hline Liberal & 19.2 & 9.0 & 9.8 & 3.4 & 6.2 \\
\hline Corporatist & 13.0 & 4.6 & 9.0 & 4.0 & 5.7 \\
\hline Southern European & 19.7 & 8.1 & 22.9 & 9.0 & 7.9 \\
\hline $\begin{array}{l}\text { Post-socialist } \\
\text { Corporatist }\end{array}$ & 16.3 & 7.1 & 65.2 & 38.4 & 12.4 \\
\hline $\begin{array}{l}\text { Post-socialist } \\
\text { Liberal }\end{array}$ & 20.7 & 9.2 & 74.1 & 42.1 & 15.6 \\
\hline
\end{tabular}

If shifting to a multidimensional perspective does not produce the desired profile, can this be achieved by shifting from a national to an EU perspective? We consider the outcomes associated with such a shift initially in relation to 'at risk of poverty'. The EUARP indicator does produce a much sharper pattern of differentiation between regimes in line with levels of societal affluence. The lowest rates of 6.1 and 9.0 per cent are again observed for the social democratic and corporatist regimes with that for the liberal cluster being marginally higher at 9.8 per cent. We then observe a sharp 
increase to 22.9 per cent for the southern European regime. A further sharp escalation then occurs for the corporatist and liberal post-socialist clusters with rates of respectively 65.2 and 74.1. Thus the desired differentiation between more and less affluent regimes is achieved but at the price of this contrast entirely dominating the results and the need to accept as valid a poverty indicator that identifies between twothirds to three-quarter of individuals in the post-socialist clusters as poor.

Adopting a multidimensional perspective at the EU level, as with the EUCP indicator, brings about an improvement in this situation. Unlike the situation at the national level, the overlap is actually greatest for the post-socialist regimes, intermediate for the corporatist and southern European clusters and lowest for the liberal and social democratic regimes. The poverty rate falls to 1.8 for the social democratic cluster, followed by the liberal and corporatist groups with levels of 3.4 and 4.0 per cent respectively. It then rises to 9.0 per cent for the southern European regime before climbing sharply to 38.4 and 42.1 per cent respectively for the corporatist and postsocialist liberal clusters. While we observe a significant reduction in poverty levels, the extent of the overlap between low income and high levels of deprivation in the post-socialist clusters require us to accept an outcome in which approximately four out of ten individuals in those societies are defined as poor.

Our final indicator the MCP measure combines a relative income approach with an EU deprivation threshold. The pattern of overlap in relation to low income and deprivation is rather different in this case. The lowest level of overlap of 23.4 per cent is observed in relation to the social democratic regime. This rises to 29.5 per cent for the liberal regime before increasing to 37 and 39 per cent respectively for the southern European and corporatist clusters. In contrast for the post-socialist regimes three out of four of those falling below the NARP threshold are also found above the EU deprivation threshold. The outcome, in terms of poverty rates, is that the lowest rate of 3.2 per cent is observed for the social democratic regime. Rather similar rates of 5.7 and 6.2 per cent are observed respectively for the corporatist and liberal clusters. A shift from an entirely relative focus on deprivation to one using a EU benchmark clearly favours the former over the latter. We then observe a gradual increase to 7.9 per cent for the southern European group, 12.4 per cent for the post-socialist 
corporatist cluster and 15.6 for the post-socialist liberal regime. The MCP measure therefore provides a pattern of regime differentiation consistent with our expectations.

In Table 2 the results deriving from a set of logistic regression summarise the welfare regime relativities for the five poverty indicators that we have employed. In each case the social democratic regime serves as the benchmark and is assigned an odds ratio of 1. All other outcomes are then expressed as multiples of the risk of being poor in the social democratic group. For the NARP group we see that variation is extremely modest with the liberal, southern European and post socialist clusters all located in a narrow range running from 2.1 to 2.3. Switching to the NCP measure serves to differentiate the social democratic regime more sharply from the remaining clusters. However, it has little effect on the pattern of differentials between the former groups. The odds ratios for the liberal, southern European and post socialist liberal regimes range from 2.8 to 3.2. Switching to the EU level in relation to 'at risk of poverty' leads the post socialist corporatist cluster odds ratio to increase to 21.3 and the postsocialist liberal regime one to 48.1. For the southern European regime a much more modest disparity of 5.5 is observed and the respective figures for the liberal and corporatist regimes are 2.0 and 1.6 .

Moving to the consistent poverty indicator at the European level a relatively similar pattern is observed. However, the odds ratio for the post-socialist liberal regime falls to 37.1 while those for the remaining regimes increase modestly. It remains true that the major contrast is between the post-socialist regimes and all others. Finally, the MCP measure, which combines both national and EU perspectives, produces the kind of graduated pattern of differentiation across welfare regimes that we would expect to be associated with a valid poverty indicator. The odds on individuals in the corporatist cluster experiencing this form of poverty are 1.9 times higher than for their counterparts in the social democratic regime. This rises to 2.4 for the liberal regime and to 2.9 for the southern European. It then rises to 3.7 and 5.4 for the corporatist and liberal post-socialist regimes. 


\begin{tabular}{|c|c|c|c|c|c|}
\hline & NARP & NCP & EUARP & EUCP & MCP \\
\hline & $\begin{array}{l}\text { odds } \\
\text { ratios* }\end{array}$ & $\begin{array}{l}\text { odds } \\
\text { ratios }\end{array}$ & $\begin{array}{l}\text { odds } \\
\text { ratios }\end{array}$ & $\begin{array}{l}\text { odds } \\
\text { ratios }\end{array}$ & $\begin{array}{l}\text { odds } \\
\text { ratios }\end{array}$ \\
\hline $\begin{array}{l}\begin{array}{l}\text { Social } \\
\text { (ref) }\end{array} \\
\end{array}$ & 1.000 & 1.000 & 1.000 & 1.000 & 1.000 \\
\hline Corporatist & 1.326 & 1.589 & 1.632 & 2.281 & 1.885 \\
\hline Liberal & 2.084 & 3.151 & 1.983 & 2.594 & 2.416 \\
\hline Southern European & 2.188 & 2.786 & 5.463 & 6.302 & 2.935 \\
\hline $\begin{array}{l}\text { Post -socialist } \\
\text { Corporatist }\end{array}$ & 1.561 & 2.052 & 21.345 & 27.005 & 3.735 \\
\hline $\begin{array}{ll}\text { Post } & \text {-socialist } \\
\text { Liberal } & \\
\end{array}$ & 2.306 & 3.225 & 48.085 & 37.193 & 5.372 \\
\hline Nagelkerke $\mathrm{R}^{2}$ & .019 & .021 & .332 & .240 & .036 \\
\hline $\mathrm{N}$ & 516,534 & 504,120 & 516,534 & 504,120 & 504,120 \\
\hline
\end{tabular}

*All significant at $\mathrm{p}<0.001$

\section{The combined effect of welfare regime and principal economic status of the HRP on poverty outcomes by type of indicator}

In this section we extend our analysis by considering not only welfare regime effects but also the impact of the principal employment status (PES) of the HRP and the manner in which they interact. In assessing the relative merits of the different poverty indicators, we have chosen to focus on the HRP PES both because it is likely to be the most powerful socio-economic predictor of poverty and because of the expectation that its impact will be significantly mediated by welfare regime. In Table 3 we show the results of a set of logistic regression with each of our five indicators in turn being taken as independent variables. The independent variables comprise a set of dummy variables relating to welfare regimes with the social democratic category taken as the reference category and a set of dummies referring to PES HRP with full-time employees as the benchmark. ${ }^{\text {ix }}$ The effect of being in part-time employment is kept uniform but the impact of all other categories is allowed to vary across welfare regime. In each case the set of interaction proves to be highly significant. In what follows we seek to illustrate graphically and discuss, for each of the poverty indicators, the patterns of relativities arising from the interaction of welfare regimes and HRP PES, variation in the latter within regime and across regimes. 


\begin{tabular}{|c|c|c|c|c|c|}
\hline & $\begin{array}{l}\text { National } \\
\text { ARP }\end{array}$ & $\begin{array}{l}\text { National } \\
\mathrm{CP}\end{array}$ & EU ARP & EU CP & $\begin{array}{l}\text { Mixed } \\
\text { CP }\end{array}$ \\
\hline & $\begin{array}{l}\text { odds } \\
\text { ratios }\end{array}$ & $\begin{array}{l}\text { odds } \\
\text { ratios }\end{array}$ & $\begin{array}{l}\text { odds } \\
\text { ratios }\end{array}$ & $\begin{array}{l}\text { odds } \\
\text { ratios }\end{array}$ & $\begin{array}{l}\text { odds } \\
\text { ratios }\end{array}$ \\
\hline Social Democratic (ref) & 1.000 & 1.000 & 1.000 & 1.000 & 1.000 \\
\hline Corporatist & $1.102^{*}$ & 1.377 & $1.169 *$ & 1.815 & 1.695* \\
\hline Liberal & $1.206 * *$ & 1.927 & 0.998 n.s & 1.269 n.s & 1.343 \\
\hline Southern European & 2.614 & 4.689 & 5.834 & 9.626 & 4.932 \\
\hline Post -socialist Corporatist & 1.832 & 2.474 & 23.083 & 39.386 & 5.475 \\
\hline Post -socialist Liberal & 2.253 & 4.187 & 46.019 & 54.913 & 7.001 \\
\hline Part-time Employees & 2.372 & 3.567 & 2.096 & 2.462 & 3.417 \\
\hline Retired & 2.622 & 2.456 & 1.652 & 1.941 & 2.244 \\
\hline Inactive & 3.541 & 6.394 & 2.555 & 4.708 & 6.369 \\
\hline Ill/disabled & 2.756 & 7.650 & 1.883 & 4.853 & 7.071 \\
\hline Unemployed & 9.177 & 24.581 & 7.756 & 22.599 & 26.073 \\
\hline Retired*C & 0.934 n.s & 0.851 n.s & $1.329 * *$ & 0.960 n.s & 0.963 n.s \\
\hline Retired*L & 1.791 & 1.005 n.s & 2.335 & $1.036 \mathrm{n} . \mathrm{s}$ & 0.964 n.s \\
\hline Retired*SE & 0.650 & 0.577 & 0.982 n.s & 0.781 n.s & 0.668 \\
\hline Retired*PSC & 0.394 & 0.593 & $0.867 *$ & $0.767 *$ & 0.485 \\
\hline Retired*PSL & $1.056 \mathrm{n.s}$ & 0.928 n.s & 3.598 & $1.309 *$ & $1.270 *$ \\
\hline Inactive*C & $1.471 * *$ & 1.334 n.s & 2.193 & $1.885 *$ & 1.156 n.s \\
\hline Inactive*L & 2.800 & 2.703 & 3.524 & 3.918 & 2.997 \\
\hline Inactive/*SE & 0.814 n.s & 0.491 & 0.986 n.s & $0.512 *$ & 0.427 \\
\hline Inactive/*PSC & 1.250 n.s & 1.099 n.s & 1.906 & 0.882 n.s & 0.829 n.s \\
\hline Inactive*PSL & $1.410 *$ & 1.063 n.s & 1.087 n.s & $0.487 *$ & 0.777 n.s \\
\hline Ill/disabled*C & 2.476 & $1.629 * *$ & 3.565 & 2.313 & $1.674 * *$ \\
\hline Ill/disabled*L & 3.608 & 2.337 & 3.915 & 2.763 & 2.469 \\
\hline Ill/disabled*SE & 1.089 n.s & $0.541 * *$ & $1.432 *$ & 0.808 n.s & $0.580 * *$ \\
\hline Ill/disabled*PSC & 1.064 n.s & $0.668 *$ & 3.330 & 1.127 n.s & 0.573 \\
\hline Ill/disabled**PSL & 2.085 & 0.922 n.s & 3.319 & 0.840 n.s & 0.887 n.s \\
\hline Unemployed*C & 1.136 n.s & 0.913 n.s & $1.262 *$ & 0.885 n.s & 0.796 n.s \\
\hline Unemployed*L & 2.454 & 1.300 n.s & 2.295 & $1.624^{*}$ & 1.409 n.s \\
\hline Unemployed*SE & 0.485 & 0.249 & 0.555 & 0.245 & 0.226 \\
\hline Unemployed*PSC & 0.930 n.s & 0.544 & 0.564 & 0.243 & 0.416 \\
\hline Unemployed*PSL & 0.858 & 0.414 & 0.802 n.s & 0.216 & 0.367 \\
\hline $\begin{array}{l}\text { Reduction in log } \\
\text { likelihood for linear model }\end{array}$ & $3,190.1$ & 1,735 & $3,344.2$ & $2,429.2$ & 2,412 \\
\hline Degrees of freedom & 20 & 20 & 20 & 20 & 20 \\
\hline Nagelkerke $\mathrm{R}^{2}$ & .117 & .147 & .334 & .307 & .157 \\
\hline $\mathrm{N}$ & 516,534 & 504,120 & 516,534 & 504,120 & 504,120 \\
\hline
\end{tabular}

All significant at $\mathrm{p}<0.001$ except $,{ }^{* *} \mathrm{P}<.01,{ }^{*} \mathrm{P}<.1$ 


\section{National ‘At Risk of Poverty’ (NARP)}

Focusing first on, in Figure 1A we illustrate the pattern of odds ratios in relation to combinations of HRP PES and welfare regime. Full-time employees in the social democratic regime are the reference category. These outcomes are produced by the combined impact of both welfare regime and HRP PES. Earlier we noted that variation in poverty levels across welfare regimes using the NARP indicator was counterintuitive. This continues to be the case when we look within categories of HRP PES. For employees, variation across welfare regimes is rather modest with the highest odds ratio of 2.6 being observed for the southern European regime. Since we have kept the impact of part-time employment constant across regime, the odds on being 'at risk of poverty' is in each case raised by a factor of 2.4. However, from Table 3 we can see that for all other categories of PES the impact on being 'at risk of poverty' is significantly greater for those in liberal welfare regimes. Being ill/disabled or inactive has a relatively strong effect in the corporatist regime but not unemployment. For post-socialist liberal regime the impact of being inactive or $\mathrm{ill} /$ disabled is also greater than in the case of the social democratic regime. Inactivity also has a stronger impact in the case of post-socialist corporatist regime but unemployment has a significantly weaker effect.

The impact of being inactive, retired and particularly being unemployed are relatively weak in the Southern European regime and indeed are lower that we might have expected on the basis of our prior expectations. As we will see, this is a pattern that recurs across indicators. On reflection this may arise because our focus is on household reference persons rather than individuals and earnings. Segmented labour markets in Spain and Italy involving sharp insider-outsider divisions which operate particularly to the disadvantage of younger workers interact with entitlement conditions so that those who benefit from segmented labour markets are likely to benefit disproportionately from the benefit system. The household reference persons we identify as excluded from the labour market may constitute a particularly favoured subset of the excluded. At the same time a segmented labour market is likely to contribute to higher 'at risk of poverty' rates among individuals where HRPs are fulltime employees.x This feature combined with high levels of intergenerational co- 
residence may play a role in producing the relatively modest employment status differentials we observe for the southern European regime. xi

The consequences of these combined effects is that, as shown in Figure 1A, relative to individuals in households with full-time employees in the social democratic regime, the highest odds on being poor among the retired of 5.7 and 6.2 are observed for the liberal and post-socialist liberal regimes. This is also true for the inactive category where the respective odds ratios are 12.0 and 11.2 and for unemployment where the respective figures are 27.2 and 17.7. In each case the social democratic regime occupies the most favourable position followed in the case of inactivity and, to a lesser extent for unemployment, by the corporatist regime. The southern European and post-socialist corporatist regimes occupy similar positions in relation to inactivity and illness/disability with both having rates rather lower than might be expected. The latter, however, occupies a less favourable position in relation to unemployment.

Figure 1A: Between Welfare Regime Variation in Levels of National 'At Risk of Poverty' by HRP PES (odds ratios relative to full-time employed HRPs in the social democratic regime)

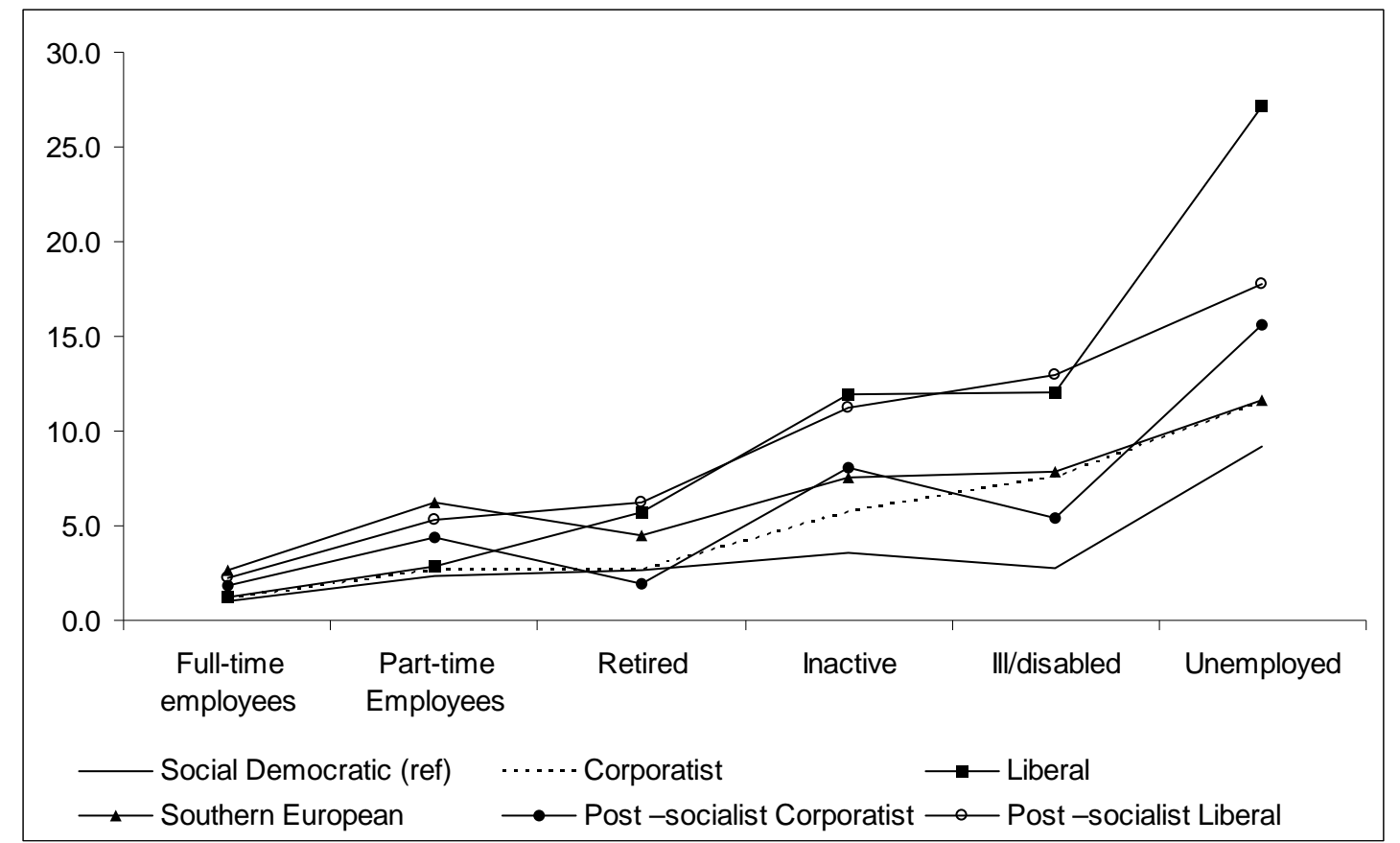

The foregoing results arise from the combined impact of welfare regime and HRP PES. At this point we focus on within regime relativities and in Figure $1 \mathrm{~B}$ we set out the pattern of relativities when full-time employees in each welfare regime are taken 
as the reference category. By far the sharpest differentials are observed for the liberal regime. Individuals in that cluster located in households where the HRP is unemployed are 22.5 times more likely than those with HRPS in full-time unemployment to be 'at risk of poverty, this figure does not rise above 10.4 for any of the remaining regimes. The liberal regime also exhibits the highest relativities relating to retirement, inactivity and illness/disability ranging from 4.7 to 9.9. Although for these categories the increment over the next highest values is nearer to 1.5 than 3 . In each case the values for the corporatist cluster comes closest to those observed for the liberal regime. In contrast, the southern European regime consistently displays low values. The remaining regimes occupy intermediate positions with ranking depending on the category under consideration, with the retired occupying a particularly favourable position in the post-socialist conservative cluster and the ill/disabled being afforded a comparable position in the social democratic group.

Figure 1B: HRP PES Relativities for National 'At Risk of Poverty' by Welfare Regime (odds ratios relative to full-time employees in each welfare regime)

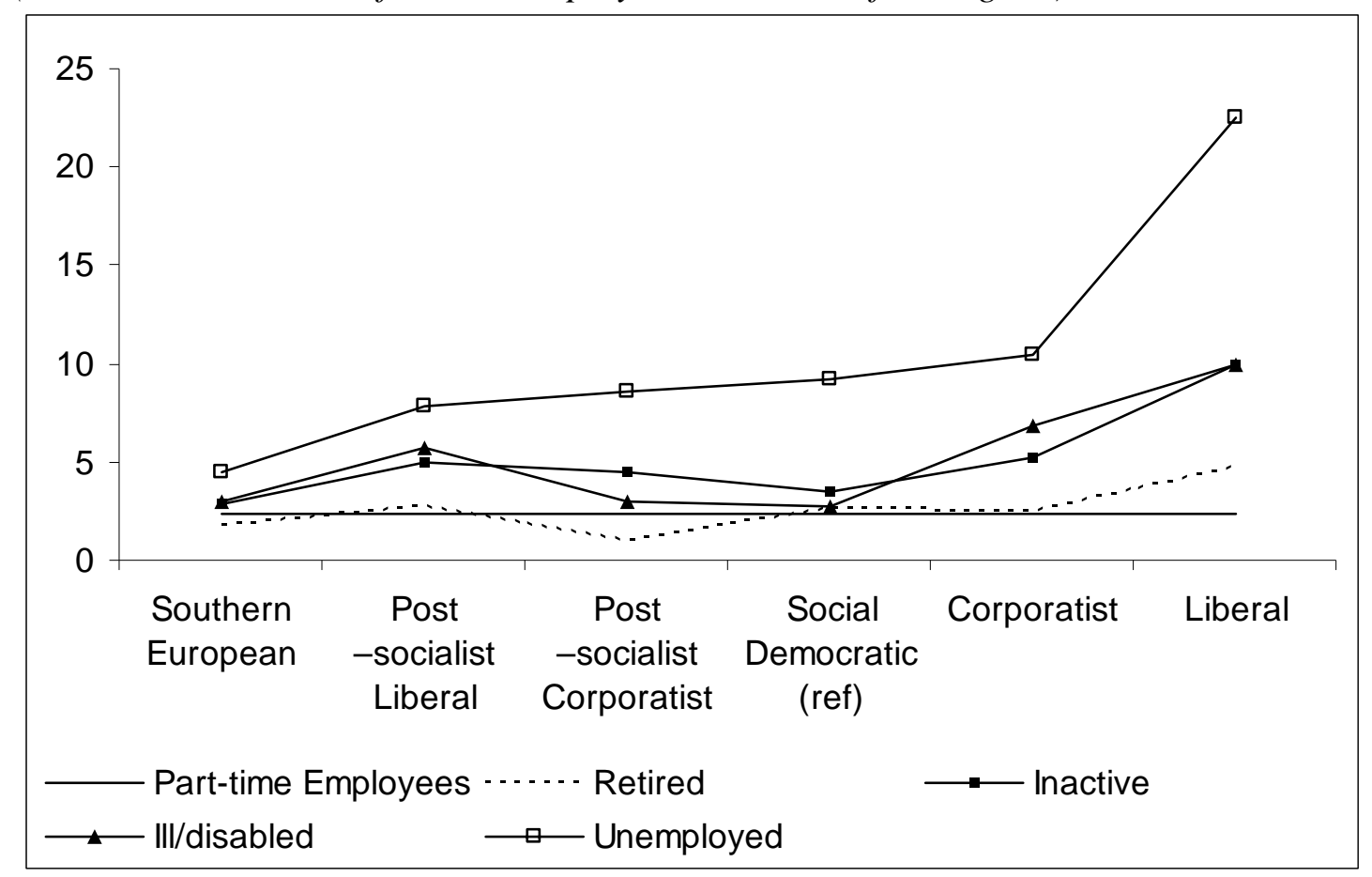

Thus variation across welfare regimes for the NARP deviates from what we would expect to be produced by a valid poverty indicator. Comparable levels of poverty for the liberal and post-socialist regimes arise, despite the less favourable position of employees in the latter, because of the substantially higher relative penalties 
associated with exclusion from the labour market in the former. Variation by PES within welfare regimes is broadly in line with our expectations with the strongest contrasts in terms of labour market exclusion effects being associated with the liberal regime and the weakest with the post-socialist clusters and, most particularly, the southern European regime.

\section{National Consistent Poverty}

At this point we shift our focus to national consistent poverty (NCP) defined in purely relative terms. In comparison with the earlier NARP results, we find that between regime differences for employees are sharper, particularly in relation to the southern European and post-socialist liberal regimes. Differentials relating to the impact of the categories reflecting labour market exclusions regimes are also more striking. However, this increased differentiation is less pronounced for the southern European and post-socialist regimes. Thus the shift to NCP measure heightens the relative differences between employees across regimes a good deal more than those relating to the remaining categories.

The combined impact of welfare regime and HRP PES is illustrated in Figure 2A. The cumulative effects are substantially greater than in the case of the NARP indicator. Thus the odds on individuals in households with unemployed HRPs in the postsocialist corporatist and liberal regimes experiencing NCP are 33.1 and 42.6 times higher than those relating to full-time employees in the social democratic regime. The corresponding figures for the NARP indicator are 15.6 and 17.7. For the inactive and ill/disabled categories in the post-socialist liberal regime the odds relative to the reference category rise to 28.5 and 29.5 respectively compared to 11.2 and 12.9 in the case of NARP. However, as with the NARP measure, the sharpest differential involves unemployed in the liberal regime whose observed odds are 61.6 times higher than full-time employees in the social democratic regime. 
Figure 2A: Between Welfare Regime Variation in Levels of National Consistent Poverty by HRP PES (odds ratios relative to full-time employed HRPs in the social democratic regime)

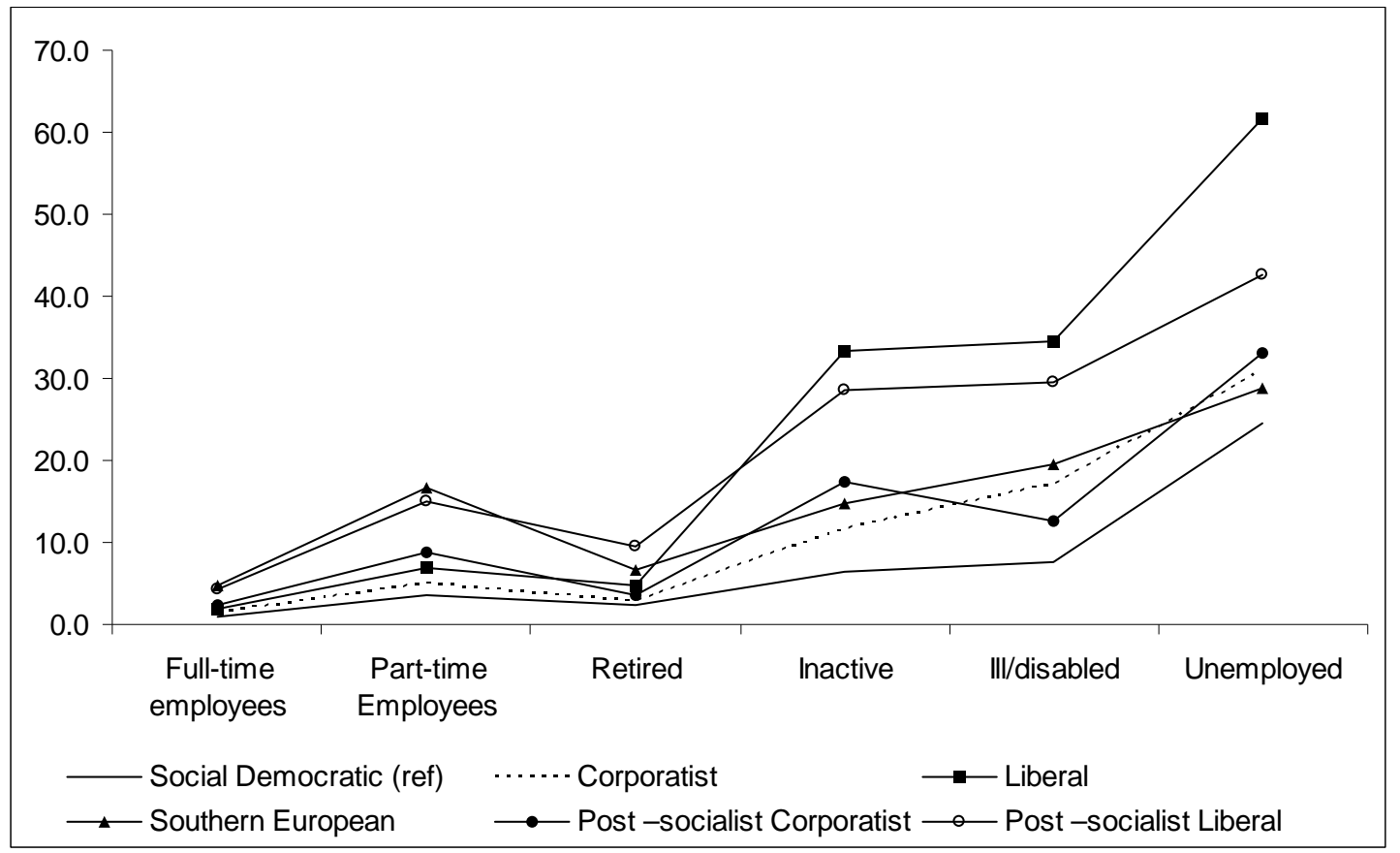

The substantially sharper pattern of overall disparities reflects the increase in the cumulative impact of welfare regime and HRP PES effects for the NCP indicator. However, the impact on regime variation within PES categories is more variable. For employees the disparity between the social democratic regime and the post-socialist liberal and southern regimes increase from 2.3 and 2.6 respectively to in turn 4.2 and 4.7. For the similar comparison involving the unemployed, while absolute odds ratios increase substantially, very little change is observed in the pattern of regime relativities which remain out of line with our expectations.

When we shift our focus to within regime relativities, we find that, as in the case of NARP, the sharpest differentials are observed for the liberal regime followed by the corporatist and social democratic regimes. However, in this case they are much more sharply distinguished from the remaining regimes. Within the liberal cluster, the odds on experiencing NCP are 32 times higher for the unemployed category than for fulltime employees. This falls slightly to 24.6 for the social democratic group and to 22.4 for the corporatist cluster. A further sharp fall to 13.4 is observed for the post-socialist corporatist regime and to 10.2 for its liberal counterpart. Finally the lowest value of 
6.1 is associated with the southern European regime. Comparable variation within the inactive and ill/disabled categories is a good deal more modest and the position of the liberal regime is more distinctive. The odds ratios for the latter are respectively two to three times higher than for any of the three least affluent clusters. While the respective figures for the corporatist cluster are in each case higher than for the latter regimes.

Figure 2B: HRP PES Relativities for National Consistent Poverty by Welfare Regime (odds ratios relative to full-time employees in each welfare regime)

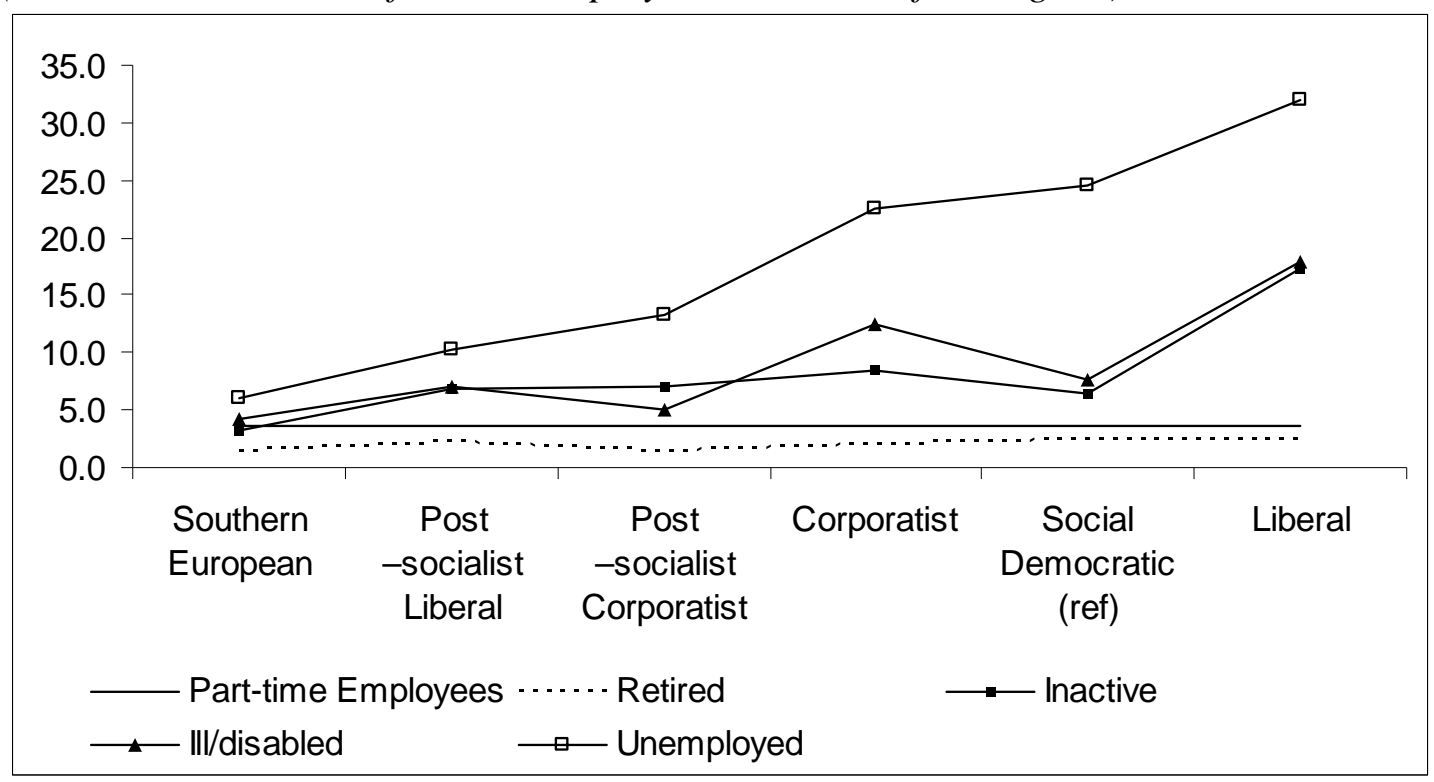

Overall, the NCP measure produces welfare regime differences that while more consistent with our prior expectations remain unsatisfactory.

\section{EU 'At Risk of Poverty’}

Switching from a national to an EU 'at risk of poverty' perspective leads to a situation, as illustrated in Figure 3, where between regime differentials, particularly those involving comparison of the post-socialist regimes with the remaining clusters, entirely over shadow within regime relativities. The latter, in fact, are remarkably similar to those observed for the NARP indicator with the strongest effects being observed for the liberal, corporatist and social democratic regimes. The only notable differences relates to a deterioration in the position of the retired category in postsocialist liberal cluster and of ill/disabled group on post-socialist corporatist group. However, within regime variation appears remarkably modest when placed in the context of the between regime disparities. 
With one exception, EUARP rates are higher for all categories of HRP PES in the southern European and post-socialist regimes than for all categories in the remaining regimes. It is necessary to accept that poverty rates for full-time employees in the post-socialist clusters are between one and a half and three times higher than for the unemployed in the corporatist and social democratic regimes. Within every category of PES, the post-socialist liberal group exhibit a distinctively high odds of being poor: followed at some distance by the post-socialist corporatist cluster and then, even further by the southern European cluster. Variation between the remaining regimes is extremely modest. For the retired and ill/disabled category the odds on experiencing EUARP are respectively 160 and 150 times higher on the post-socialist liberal cluster than in the social democratic regimes, for the remaining categories the figure ranges between the high thirties and high forties. For the post-socialist conservative group the highest disparities of 76 and 43 relate to illness/disability and being inactive. For the remaining categories the inequalities range between 23:1 for employees to $13: 1$ for the unemployed.

In terms of within regime relativities in the effect of HRP PES, the EUARP indicator produces outcomes extremely similar to the NARP measure. However, such differences are almost irrelevant when placed in the context of the post-socialist regime effects. 
Figure 3: Between Welfare Regime Variation in Levels of EU 'At Risk of Poverty' by HRP PES (odds ratios relative to full-time employed HRPs in the social democratic regime)

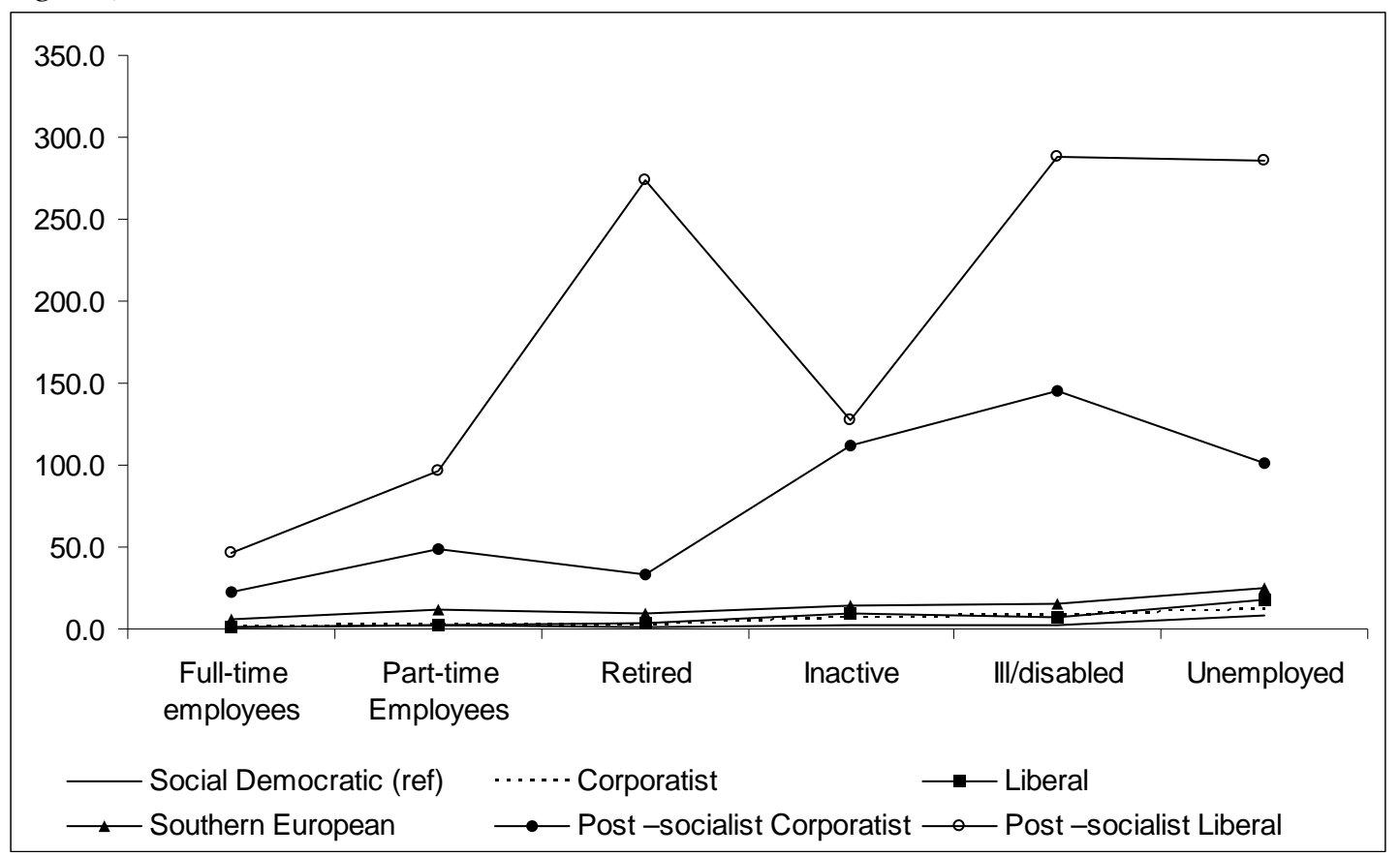

\section{EU Consistent Poverty}

Each time we shift from a national to an EU perspective, the average welfare regime effects are much higher. Similarly, when we move from an 'at risk of poverty' approach to a consistent poverty perspective the average PES effects increase sharply. However, once again in moving from EUARP to the EUCP we observe a sharp pattern of interaction between welfare regime and HRP PES, with relativities relating to the latter being substantially weaker in the southern European and post-socialist clusters. However, the scale of the between regime differences dominate.

From Figure 4 we can see that, as with the EU ARP indicator, the overriding contrast is between the post-socialist regimes and all others with 11 of the 12 highest odds ratios being associated with these clusters. However, on this occasion there is much less divergence between the two post-socialist clusters. In relation to the comparison of the HRP being unemployed or ill/inactive in comparison with full-time employees they each experience a similar level of relative disadvantage reflected in odds ratios exceeding 200. For the remaining groups the relevant figure ranges from 55 for employees to 140 for the retired for the post-socialist liberal regime while for its 
corporatist counterpart the range goes from 39 for employees to 164 for the inactive. Poverty rates for full-time employees in the post-socialist clusters are comparable to those for the unemployed in the more affluent regimes.

The within country relativities for the liberal, social democratic and corporatist regimes are very similar to those prevailing in respect to the national consistent poverty indicator and consequently more substantial than in the case of the EUARP measure. For the post socialist and southern European regimes the odds ratio relating to the within group comparison of the unemployed with employees is approximately 5 in each case. It rises to 20 for the corporatist group to 23 for the social democratic and to 37 for the liberal regime. While such effects are a good deal more substantial than for the EUARP measure, between regime effects are of such a magnitude as to make them seem modest when viewed in this context.

Figure 4: Between Welfare Regime Variation in Levels of EU Consistent Poverty by HRP PES (odds ratios relative to full-time employed HRPs in the social democratic regime)

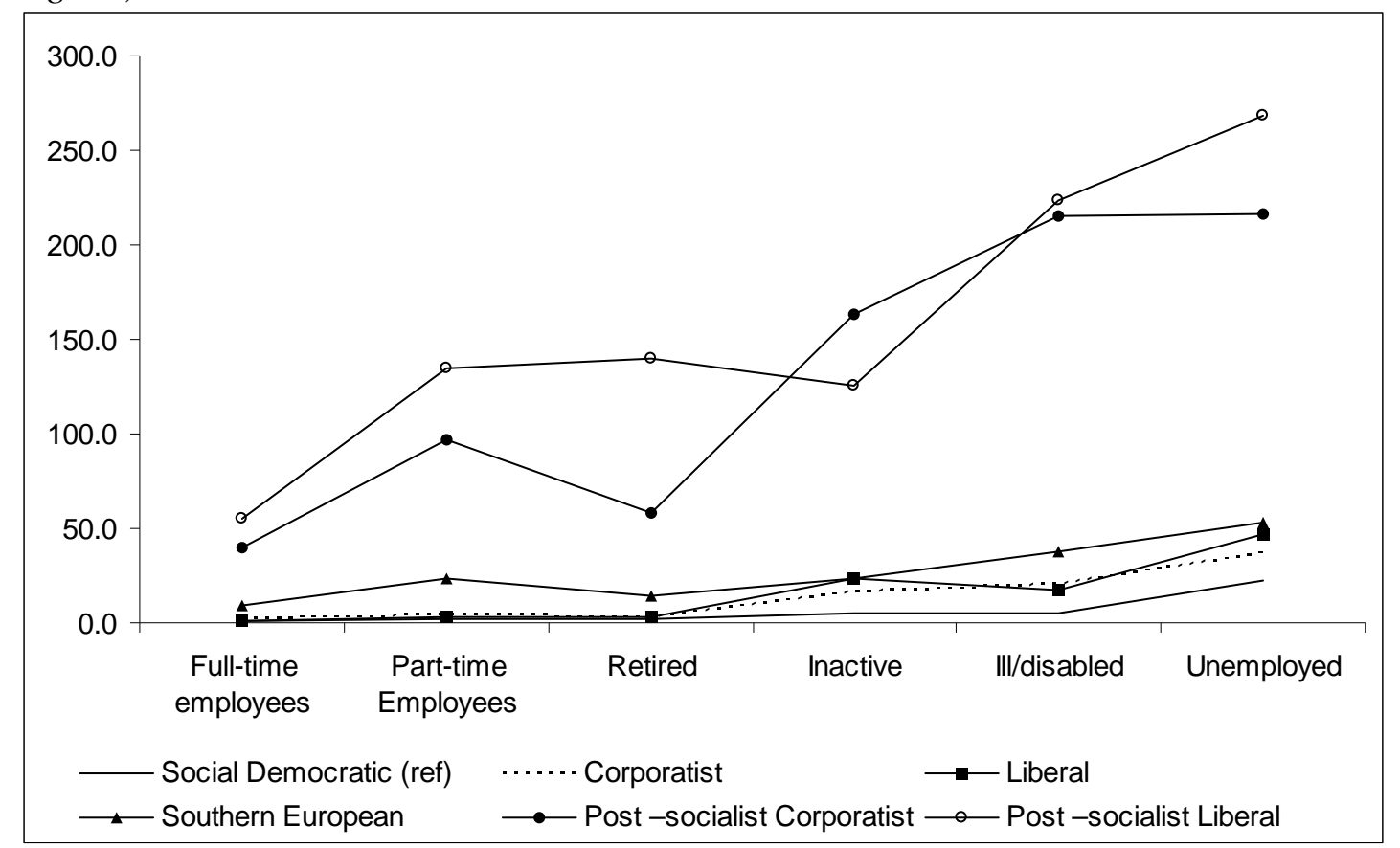




\section{Mixed Consistent Poverty}

In this section we focus on the mixed consistent poverty measure where individuals are defined as poor when they are both 'at risk of poverty' and above the EU deprivation threshold that corresponds to the EUARP line. At an overall level, the indicator produces a pattern of between regime differentiation consistent with our expectations. From Figure 5A we can see that these relativities are broadly maintained within categories of HRP PES.

Variation in the odds ratio for employees relative to those in the social democratic regimes rises from modest levels of 1.3 and 1.7 for the liberal and corporatist regimes to 4.9 for the southern European cluster and finally to 5.5 and 7.0 respectively for the corporatist and liberal post-socialist clusters. For the retired group the figure rises from 2.2 for the social democratic regime to 2.9 and 3.7 for the liberal and corporatist clusters to 7.4 and 6.0 for the southern European and post-socialist corporatist cluster before escalating to 20.0 for the post-socialist liberal regime. For the inactive group the odds ratio goes from 6.4 in the social democratic regime to 12.5 to the corporatist cluster. As with the remaining categories relating to labour market exclusion, the odds ratio for the southern European regime at 13.4 is relatively close to that for the corporatist regime. The figure for the liberal regime is substantially higher at 25.6 and close to that of 28.9 for the post-socialist corporatist regime. The level peaks at 34.6 for the post-socialist liberal regime.

For illness and disability the major contrast is between the social democratic regime and the post-socialist liberal group with odds ratios of respectively 7.1 and 43.9. For the remaining regimes the relevant odds ratio varies between 20.1 for the corporatist regime to 23.4 for the liberal cluster. The lowest odds ratio for the unemployed group of 26.1 again relates to the social democratic regime. It is followed, somewhat unexpectedly, by the southern European regime with a value of 29.1. It rises to 35.2 for the corporatist cluster before increasing to 49.3 for the liberal regime. Further increases are then observed to 59.4 and 67.0 respectively for the corporatist and liberal post-socialist clusters. 
The pattern of between regime relativities is broadly consistent with our expectations with the social democratic regime enjoying the most favourable position in every case and the post-liberal occupying the least favourable. The post-corporatist group is closest to the latter in four of the six cases while as we anticipated it enjoys a relatively favourable position in relation to the retired. The corporatist and liberal regimes display similar patterns of risk for the employee and retired categories but the former enjoys substantial advantages in relation to inactivity and unemployment. The major deviation from our prior expectations relates to the odds on such poverty for the southern European regime associated with being excluded from the labour market. One possible explanation for this outcome is that effects of labour market segmentation and for the HRP and household structure combine with the significant role of the 'grey' labour market in influencing both the income and deprivation components of the MCP indicator.

Figure 5A: Between Welfare Regime Variation in Levels of Mixed Consistent Poverty by HRP PES (odds ratios relative to full-time employed HRPs in the social democratic regime)

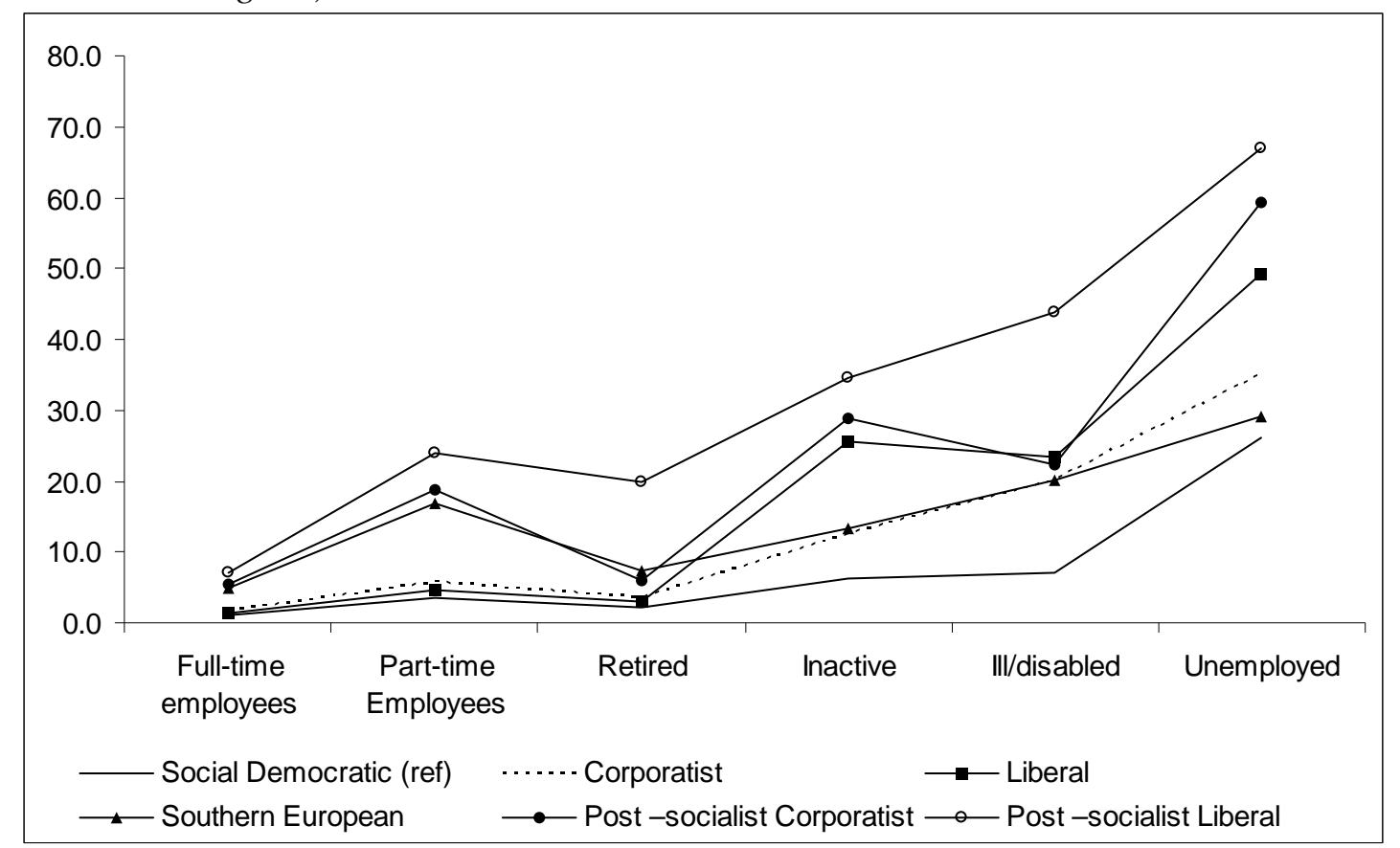

As we can see from Figure 5B, the pattern of within welfare regime relativities relating to HRP PES is very similar to that observed in relation to the national consistent poverty measure with the sharpest pattern of variation being observed for the liberal regime, followed by the social democratic and corporatist regime. 
Differentials are a good deal more modest for the post-socialist clusters and are minimised for the southern European regime.

Figure 5B: HRP PES Relativities for Mixed Consistent Poverty by Welfare Regime (odds ratios relative to full-time employees in each welfare regime))

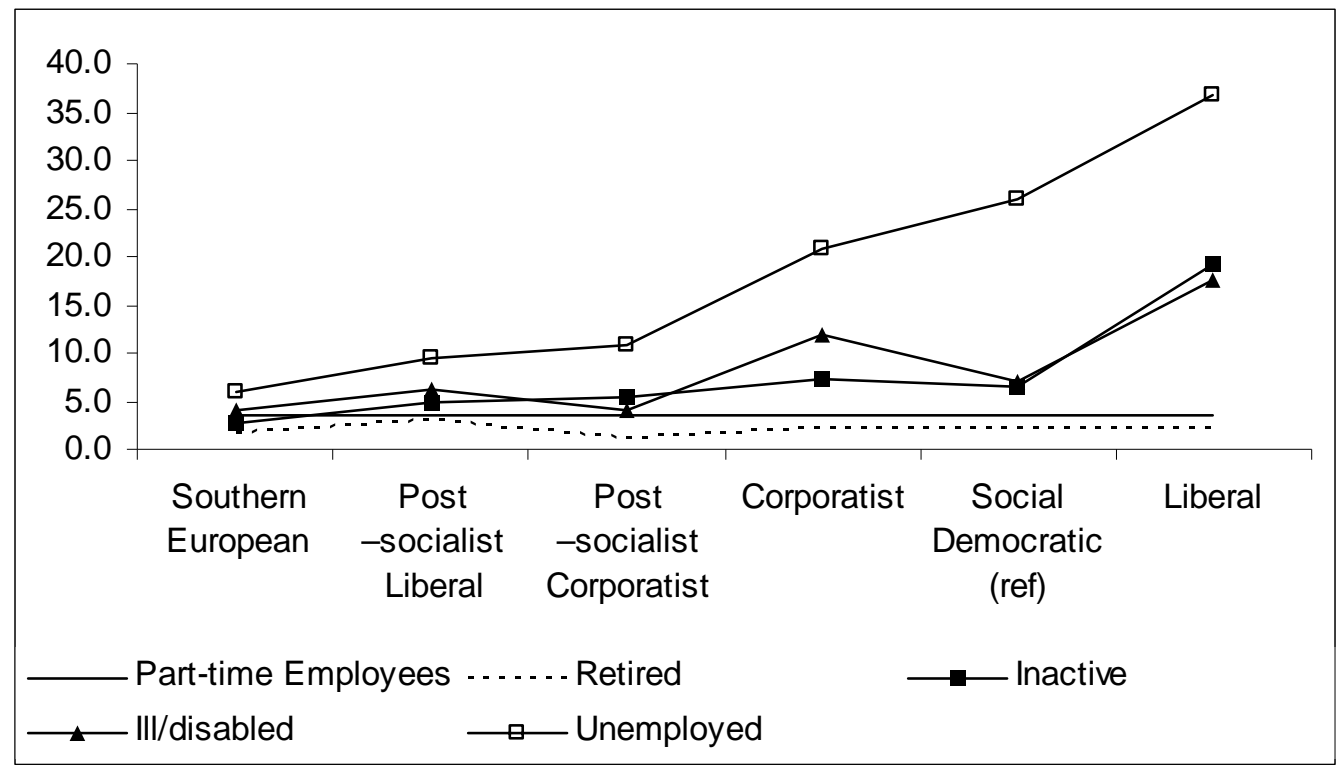

The MCP measure, as well as identifying a minority as poor in each welfare regime and producing overall welfare regime variation along the hypothesised lines, also reveals patterns of within and between welfare regimes that are broadly consistent with our prior expectations.

\section{Economic Stress Levels by Welfare Regime and Principal Economic Status}

As a final means of assessing the relative merits of the various poverty indicators, in this section we consider the relationships between subjectively experienced economic stress and welfare regime and poverty outcomes. In Table 4 we set out the results for a set of regression in which welfare regime, poverty outcomes and their interactions are regressed on each of the five indicators.

A number of key findings emerge. For all five measures, differences in level of economic stress among the non-poor between the post-socialist liberal regime and the social democratic one are less than we might have expected. However, this is particularly true when we focus on the EU measures and extends to the post-socialist 
conservative cluster. The conclusion extends to the poor but with some somewhat less force as the relevant interactions are generally positive. The within regime impact of poverty is also significantly lower in every case for the corporatist regime than for the remaining regimes. This reflects a pattern whereby stress levels for the poor are in each case similar to those for the social democratic regime while the corresponding levels for the non-poor are very similar to those in the liberal regime.

\begin{tabular}{|c|c|c|c|c|c|}
\hline & $\begin{array}{l}\text { National } \\
\text { ARP }\end{array}$ & EU ARP & National CP & Mixed CP & EU CP \\
\hline & Odds Ratios & Odds Ratios & Odds Ratios & Odds Ratios & Odds Ratios \\
\hline \multicolumn{6}{|l|}{$\begin{array}{l}\text { Welfare } \\
\text { Regime }\end{array}$} \\
\hline $\begin{array}{l}\text { Social } \\
\text { Democratic } \\
\text { (ref) }\end{array}$ & 1.000 & 1.000 & 1.000 & 1.000 & 1.000 \\
\hline Corporatist & 2.479 & 2.241 & 2.415 & 2.405 & 2.285 \\
\hline Liberal & 1.787 & 1.847 & 1.844 & 1.914 & 1.965 \\
\hline $\begin{array}{l}\text { Southern } \\
\text { European }\end{array}$ & 5.400 & 4.619 & 5.862 & 5.772 & 5.186 \\
\hline $\begin{array}{l}\text { Post- } \\
\text { socialist } \\
\text { Corporatist }\end{array}$ & 5.182 & 2.291 & 5.608 & 5.108 & 2.714 \\
\hline $\begin{array}{l}\text { Post- } \\
\text { socialist } \\
\text { Liberal }\end{array}$ & 3.326 & $0.971 \mathrm{n} . \mathrm{s}$ & 3.560 & 3.119 & 1.218 \\
\hline Poor & 3.676 & 2.879 & 11.223 & 10.781 & 9.000 \\
\hline Poor*C & 0.466 & 0.579 & 0.360 & 0.312 & 0.325 \\
\hline Poor*L & 1.146 n.s & 1.552 & 0.910 n.s & $1.232 \mathrm{n.s}$ & $1.605 * *$ \\
\hline Poor*SE & $0.890 *$ & 1.065 n.s & 0.909 n.s & 0.979 n.s & 1.056 n.s \\
\hline Poor*PSC & 1.267 & 1.664 & 1.809 & 1.006 n.s & 1.093 n.s \\
\hline Poor*PSL & $1.213^{*}$ & 2.083 & 1.015 n.s & 0.856 n.s & $1.357^{* *}$ \\
\hline $\begin{array}{l}\text { Reduction in } \\
\text { log } \\
\text { likelihood } \\
\text { for linear } \\
\text { model }\end{array}$ & $1,433.5$ & $1,735.9$ & $1,147.5$ & $1,224.2$ & $1,139.2$ \\
\hline $\begin{array}{ll}\begin{array}{l}\text { Degrees of } \\
\text { freedom }\end{array} & \\
\end{array}$ & 5 & 5 & 5 & 5 & 4 \\
\hline $\begin{array}{l}\text { Nagelkerke } \\
\mathrm{R}^{2}\end{array}$ & .158 & .170 & .186 & .197 & .242 \\
\hline $\mathrm{N}$ & 525,472 & 525,472 & 512,904 & 512,904 & 512,904 \\
\hline
\end{tabular}

All significant at $\mathrm{p}<0.001$ except $, * * \mathrm{P}<.01, * \mathrm{P}<.1$ 
The impact of indicators that capture consistent poverty on economic stress is in every regime substantially higher than for the 'at risk of poverty'. In Figure 6 we illustrate welfare regime variation in the within regime impact of poverty for each of the five indicators. For the NARP measure the odds ratio for poor versus non-poor is 1.7 and for the remaining clusters it varies between 3.3 for the southern European regime and 4.7 for the post-socialist corporatist. The figures for the EUARP indicator are extremely similar but rise to 6.0 for the post-socialist liberal group. For the NCP indicator the odds ratio for the corporatist regime is 4.0. The post-socialist corporatist cluster constitutes an outlier of a quite different sort in displaying an odds ratio of 20.3. The remaining values are found in the range running from 10.2 to 11.4. For the EU CP measure the corporatist values is 2.9 and for the remaining regimes the figure goes from 9.0 to 14.4. Finally for the MCP the corporatist value is 3.4 and the remaining observation are located in the range running from 9.2 to 13.3. In both of the previous cases the highest values is associated with the liberal regime.

Typically the relativities in subjective economic stress are of magnitude three times greater than those observed in relation to the 'at risk of poverty' measures. On the other hand, there is very little to choose between the three consistent poverty measures in terms of their capacity to discriminate between those experiencing economic stress and the remainder of the population.

Figure 6: The Impact of Poverty by Type of Indicator within Welfare Regime (Odds ratios relative to reference category of non-poor within each regime)

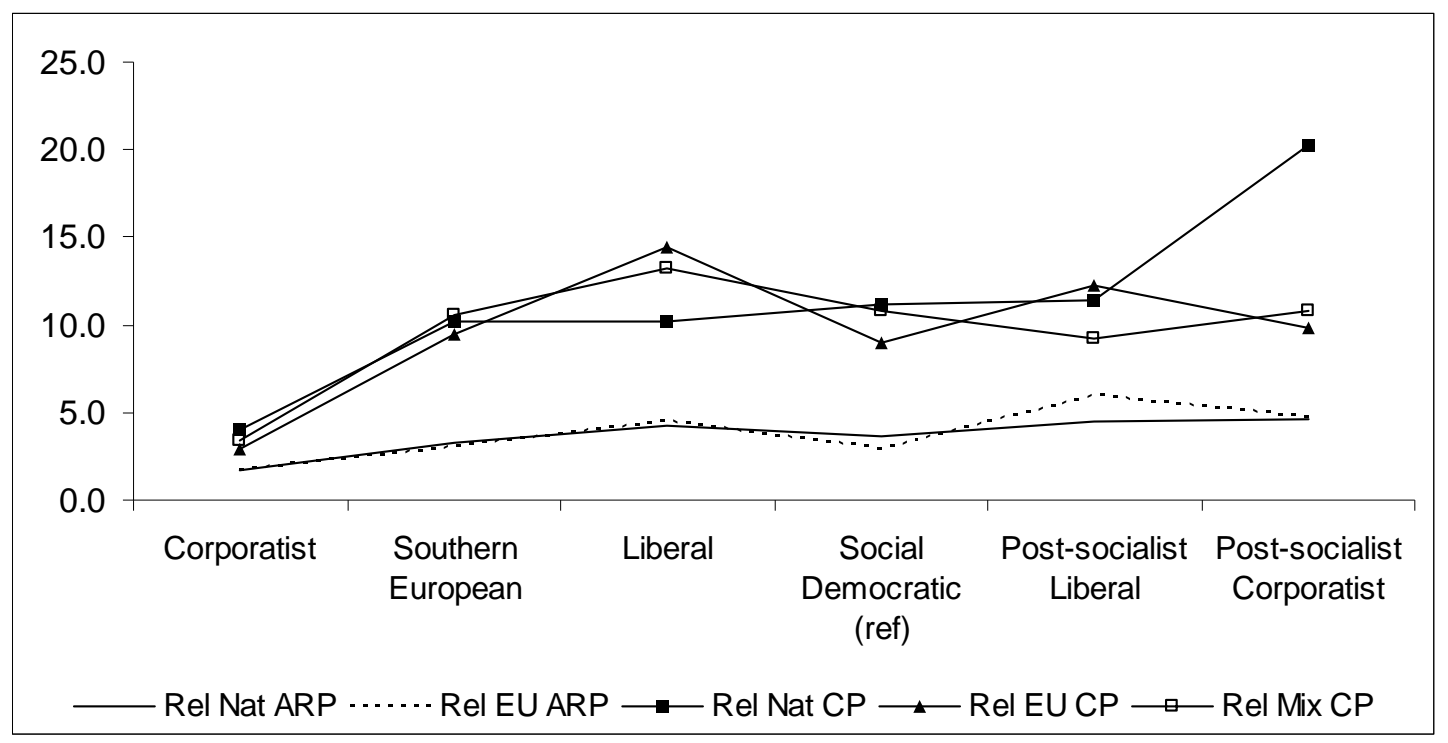




\section{Conclusions}

In this paper we have sought to assess the extent to which the relative merits of different poverty indicators can be illuminated by considering welfare regime and socio-economic variation poverty levels and patterns and in the consequences of different poverty outcomes for subjectively experienced economic stress.

In pursuing this objective, we have considered indicators of 'at risk of poverty' and consistent poverty at both national and EU levels together with a mixed consistent poverty measure that combines information on relative income at the national level with relative material deprivation. In assessing the construct validity of the various indicators, we have taken into account patterns of between and within welfare regime variation and relationships to subjective economic stress.

For the national 'at risk of poverty' we observe the counterintuitive pattern of variation in relation to level of prosperity of the welfare regimes that has led governments to be reluctant to accept it as appropriate social indication. Patterns of association with HRP PES and economic stress take the expected form but the strength of the associations is weaker than in the case of the consistent poverty indicators. The impact of HRP PES is strongest for the liberal regime and weakest for the southern European with the retired enjoying particular advantage in the corporatist regimes. Crucially between regime variation continues to display a counterintuitive pattern within categories of HRP PES.

Switching to a consistent poverty perspective reduces the level of poverty but does nothing to produce a set of welfare regime difference more consistent with our prior expectations. In each case the limited ability of the NARP to capture exclusion from customary living patterns and activities due to a lack of resources is reflected in the limited overlap between falling below the national income threshold and being found above the corresponding deprivation benchmark. However, contrary to the argument that the limitations of the NARP are directly related to EU enlargement it is actually least effective in capturing the most deprived in the social democratic and corporatist regimes. Since the overlap is rather similar in the liberal and post-socialist regimes their relative position is unaffected. Variation across categories of HRP PES are 
much sharper than in the case of NARP and the pattern of interaction whereby the impact of labour market exclusions is a good deal sharper than in the more affluent welfare regimes is also much more pronounced and the relationship to economic stress is substantially stronger. On the grounds of its ability to capture within country relativities the NCP measure is clearly preferable but neither produces the kind of between regime variation that we might expect of a valid measure of poverty either overall or within PES categories.

Shifting to an EU 'at risk of poverty' indicator produces the desired differentiation between welfare regimes in terms of levels of prosperity. However, this progress comes at the price of this contrast entirely dominating results. It becomes necessary to accepting that between two-thirds to three-quarters of those in the post-socialist regimes are to be counted as poor and that full-time employees in these clusters are more likely to experience such poverty than the unemployed in the more affluent regimes. These outcomes are less stark when one adopts a multidimensional perspective with substantially greater variation in relation to both HRP PES and economic stress. However, it remains necessary to accept that 40 per cent of the post socialist cluster are in poverty and that full-time employees in these regimes are at least equally likely to experience poverty as the unemployed in the affluent regimes. The evidence provides further support for the conclusion of Marlier et al (2007-154155) that a EU-wide approach by failing to take into account differences in "the significance of goods in social functioning” would miss people in richer countries who are experiencing genuine exclusion from their own society while counting substantial numbers in the poorer societies who are not experiencing such exclusion.

The mixed consistent poverty indicator produces a significant pattern of differentiation between welfare regimes in line with our prior expectations. Clear patterns of differentiation are also observed in relation to HRP PES. In addition, welfare regime relativities are broadly maintained with categories of HRP PES. As with the other consistent poverty measures, PES effects are strongest in the liberal regime and its distinctive character is seen to lie not in high levels of poverty as such but in the scale of disadvantage associated with labour market exclusion and, in particular unemployment. In contrast, in the southern European and post-socialist 
regimes higher overall levels of MCP are accompanied by weaker within regime PES differentials with the consequence that between regime differentials are sharper for full-time employees that for those excluded from the labour market. Levels of poverty for the full-time employed are significantly lower than for the unemployed irrespective of which regime we consider. Finally those exposed to MCP are substantially more likely to experience economic stress and this is particularly true for both liberal regimes.

Our findings lead us to agree with Fahey (2007) that in understanding poverty in an enlarged EU it is necessary to consider indicators other than the 'at risk of poverty' measure. However, our analysis suggests that the EU-wide 'at risk of poverty' measure based on 60 per cent of median equivalent income in the EU as a whole proposed by Fahey (2007:45) would prove to be a less than ideal choice. Instead we propose using a measure such as the mixed consistent poverty measure developed here. The latter, in particular, unlike the EU 'at risk of poverty' indicator produces a set of results that are largely in line with our expectations of how a valid poverty measure should behave. Such an approach would allow us to achieve the stated EU objective of assessing the scale of exclusion from minimally acceptable level of standards of living in individual countries while also assessing the extent to which the whole population of Europe is sharing in the benefits of high average prosperity.

\section{Acknowledgements}

We are grateful to the EQUALSOC EU Network of Excellence for granting access to the EU-SILC 2006 data set.

\section{References}

Alber, J., Fahey, T. and Saraceno, C. (2007), 'Introduction: EU Enlargement and Quality of Life: The Context and Purpose of the Book', in Alber, J., Fahey, T. and Saraceno, Handbook of Quality of Life in the Enlarged European Union, Oxon: Routledge

Berthoud, R. (2004), 'How Can Deprivation Indicators Help Us to Understand Poverty?'. Benefits, 14(2), pp 103-114. 
Brandolini, A. (2007), 'Measurement of Income Distribution in Supranational entities: The Case of the European Union', in J. Micklewright and S. Jenkins (eds.), Inequality and Poverty Re-examined, Oxford: Oxford University Press.

Bukodi, E. and Robert, P. (2007) Occupational Mobility in Europe, European Foundation for the Improvement of Living and Working Conditions, Luxembourg, Office for Official Publications of the European Communities.

Callan, T., Nolan, B. and Whelan, C. T. (1993), 'Resources, Deprivation and the Measurement of Poverty’, Journal of Social Policy, 22, 2:141-172.

Cedefop (2001), The transition from education to working life. Key data on vocational training in the European Union, Cedefop Reference series, Luxembourg, Office for Official Publications of the European Communities.

European Commission (2004). A New Partnership for Cohesion. Convergence Competitiveness Cooperation. Third Report on Economic and Social Cohesion. Luxembourg: Office for Official Publications of the European Communities.http://europa.eu.int/comm/regional_policy/sources/docoffic/official/rep orts/cohesion3/cohesion3_en.htm (accessed July 2004).

Fahey. T. (2007), 'The Case for an EU-wide measure of Poverty', European Sociological Review, 23,1, 35-47.

Förster, M. F. (2005), 'The European Social Space Revisited: Comparing Poverty in the Enlarged European Union', Journal of Comparative Policy Analysis, 7,1, 29-48.

Gallie, D. and Paugam, S. (2000), 'The Experience of Unemployment in Europe', in D. Gallie and S. Paugam (eds.) Welfare Regimes and the Experience of Unemployment in Europe, Oxford: Oxford University Press.

Guio, A.-C. (2005a), Material Deprivation in the EU, Statistic in Focus, 21/2005.

Guio, A.-C. (2005b), Income Poverty and Social Exclusion in the EU25', Statistic in Focus 13/2005

Juhász, G. (2006), 'Exporting or Pulling Down? The European Social Model and Eastern Enlargement of the EU', European Journal of Social Quality, 6,1: 82-107

Iacovou, M. (2004) 'Patterns of Family Living', in R. Bertoud and M. Iacovu (eds), in Social Europe: Living Standards and Welfare States, Cheltenham, Edward Elgar. Ianelli, C. and Soro-Bonamatí, A. (2003) 'Transition Pathways in Italy and Spain: Different patterns similar vulnerability' in Müller, W. and Gangl. M., Transitions from Education to Work in Europe, Oxford University Press. 
Kangas, O. and Ritakallio, V (2007), 'Relative to What? Cross National Pictures of European Poverty Measured by Regional, National and European Standards', European Societies, 9,2:119-145.

Marlier, E, Atkinson, A., Cantillon and Nolan, B. (2007), The EU and Social Inclusion :Facing the Challenges, Bristol: Policy press

Muffels. R. and Fouarge, D. (2004), 'The Role of European Welfare States in Explaining Resources Deprivation’ Social Indicators Research, 68, 3: 299-330.

Muffels, R.J.A. and Luijkx, R., (2006), 'Globalisation and male job mobility in European welfare states', in Blossfeld, H.-P., Mills, M. and Bernardi, F. (eds.), Globalisation, uncertainty and men's careers: An international comparison, Cheltenham, UK and Northampton, MA, Edward Elgar.

Nolan, B. and Whelan, C.T. (2007), 'On the Multidimensionality of Poverty and Social Exclusion’ in Micklewright, J. and Jenkins, S. (eds.) Poverty and Inequality: New Directions, Oxford: Oxford University

Plolavieja, J. (2008), Unemployment Insurance, Employment Protection and active Labour Markets, AIAS, Masterdam, October 2008

Tohara, L. and Malo, M. (2000). 'The Spanish experiment: Pros and Cons of Flexibility at the Margin', in G. Esping-Andersen and M. Regini (eds) Why Regulate Labour Markets? , Oxford: Oxford University Press.

Townsend, P. (1979), Poverty in the United Kingdom Penguin, Harmondsworth

Whelan, C. T. (2007), 'Understanding the Implications of Choice of Deprivation Index for Measuring Consistent Poverty in Ireland', Economic and Social Review, 38, 2, 211-234

Whelan, C. T. and Maître, B. (2007), 'Income, Deprivation and Economic Stress in an Enlarged European Union’, Social Indicators Research, 83:309-329

Whelan, C.T., Nolan B. \& Maître B. (2008), 'Measuring Material Deprivation in the Enlarged EU’, ESRI Working Paper 249 www.esri.ie 
${ }^{\mathrm{i}}$ Increasing attention has also been devoted to measurement at the sub-national level which raises a range of issues that go beyond the scope of this paper (see Berthoud, 2004 and Kangas and Ritakallio, 2007).

${ }^{\text {ii }}$ For a recent review of this evidence see Nolan and Whelan (2007).

iii See Callan et al (1993) and Whelan (2007).

${ }^{\text {iv }}$ For such accounts see Guio (2005 a \&b).

$\mathrm{v}$ The proper allocation of the Netherlands is a matter for debate. We follow Muffels and Luijkx and Muffels and Fouarge (2004) in locating it in the social democratic cluster.

${ }^{\text {vi }}$ Although the latter is less true of Ireland.

vii See Whelan et al (2008) for further details.

viii See Whelan and Maître (2007)

${ }^{\text {ix }}$ In the latter case we have excluded individuals in households where the reference person is in fulltime education and training because of difficulties in interpreting the consequences of being in this category. The equations have bee estimated with robust standard errors to allow for the clustering of individuals within households

${ }^{x}$ See Polavieja (2008), See Tohara and Malo (2000) and Ianelli and Soro-Bonamatí (2003)

${ }^{x i}$ See Gallie and Paugam (2000: 13-18), Iacovou (2004). 


\begin{tabular}{lll}
\hline Year & Number & Title/ Author(s) \\
ESRI Authors/Co-authors /talicised
\end{tabular}

2008

262

Fuel Poverty in I reland: Extent,

Affected Groups and Policy Issues

Sue Scott, Seán Lyons, Claire Keane, Donal McCarthy and Richard S.J. Tol

261 The Misperception of Inflation by I rish Consumers

David Duffy and Pete Lunn

260 The Direct Impact of Climate Change on Regional Labour Productivity

Tord Kjellstrom, R Sari Kovats, Simon J. Lloyd, Tom Holt, Richard S.J. Tol

259

Damage Costs of Climate Change through Intensification of Tropical Cyclone Activities: An Application of FUND

Daiju Narita, Richard S. J. Toland David Anthoff

258

Are Over-educated People Insiders or Outsiders? A Case of J ob Search Methods and Over-education in UK

Aleksander Kucel, Delma Byrne

257

Metrics for Aggregating the Climate Effect of Different Emissions: A Unifying Framework

Richard S.J. Tol, Terje K. Berntsen, Brian C. O'Neill, Jan S. Fuglestvedt, Keith P. Shine, Yves Balkanski and Laszlo Makra

256 Intra-Union Flexibility of Non-ETS Emission Reduction Obligations in the European Union

Richard S.J. Tol

255 The Economic I mpact of Climate Change Richard S.J. Tol

$254 \quad$ Measuring International Inequity Aversion Richard S.J. Tol

253 Using a Census to Assess the Reliability of a National Household Survey for Migration Research: The Case of I reland Alan Barrett and Elish Kelly 
Risk Aversion, Time Preference, and the Social Cost of Carbon

David Anthoff, Richard S.J. Tol and Gary W. Yohe

251

The Impact of a Carbon Tax on Economic Growth and Carbon Dioxide Emissions in I reland

Thomas Conefrey, John D. Fitz Gerald, Laura Malaguzzi Valeri and Richard S.J. Tol

250

The Distributional Implications of a Carbon Tax in I reland

Tim Callan, Sean Lyons, Susan Scott, Richard S.J. Tol and Stefano Verde

Measuring Material Deprivation in the Enlarged EU Christopher T. Whelan, Brian Nolan and Bertrand Maître

Marginal Abatement Costs on Carbon-Dioxide Emissions: A Meta-Analysis

Onno Kuik, Luke Brander and Richard S.J. Tol

Incorporating GHG Emission Costs in the Economic Appraisal of Projects Supported by State Development Agencies

Richard S.J. Tol and Seán Lyons

$246 \quad$ A Carton Tax for Ireland

Richard S.J. Tol, Tim Callan, Thomas Conefrey, John D. Fitz Gerald, Seán Lyons, Laura Malaguzzi Valeri and Susan Scott

245 Non-cash Benefits and the Distribution of Economic Welfare

Tim Callan and Claire Keane

244 Scenarios of Carbon Dioxide Emissions from Aviation

Karen Mayor and Richard S.J. Tol

243 The Effect of the Euro on Export Patterns: Empirical Evidence from Industry Data

Gavin Murphy and Iulia Siedschlag

242 The Economic Returns to Field of Study and Competencies Among Higher Education Graduates in I reland

Elish Kelly, Philip O'Connell and Emer Smyth 
Aviation and the Environment in the Context of the EU-US Open Skies Agreement Karen Mayor and Richard S.J. Tol

Yuppie Kvetch? Work-life Conflict and Social Class in Western Europe

Frances McGinnity and Emma Calvert the Interactions between Immigrant Characteristics, I mmigrant Welfare Dependence and Welfare Policy Alan Barrett and Yvonne McCarthy

How Local is Hospital Treatment? An Exploratory Analysis of Public/Private Variation in Location of Treatment in I rish Acute Public Hospitals Jacqueline O'Reilly and Miriam M. Wiley

The Immigrant Earnings Disadvantage Across the Earnings and Skills Distributions: The Case of Immigrants from the EU's New Member States in I reland

Alan Barrett, Seamus McGuinness and Martin O'Brien

235 Europeanisation of Inequality and European Reference Groups

Christopher T. Whelan and Bertrand Maître

$234 \quad$ Managing Capital Flows: Experiences from Central and Eastern Europe

Jürgen von Hagen and Iulia Siedschlag

ICT Diffusion, Innovation Systems, Globalisation and Regional Economic Dynamics: Theory and Empirical Evidence

Charlie Karlsson, Gunther Maier, Michaela Trippl, I ulia Siedschlag, Robert Owen and Gavin Murphy

232 Welfare and Competition Effects of Electricity Interconnection between Great Britain and I reland Laura Malaguzzi Valeri 
Is FDI into China Crowding Out the FDI into the European Union?

Laura Resmini and I ulia Siedschlag

230

Estimating the Economic Cost of Disability in I reland

John Cullinan, Brenda Gannon and Seán Lyons

229

Controlling the Cost of Controlling the Climate: The I rish Government's Climate Change Strategy

Colm McCarthy, Sue Scott

228

The Impact of Climate Change on the BalancedGrowth-Equivalent: An Application of FUND

David Anthoff, Richard S.J. Tol

Changing Returns to Education During a Boom? The Case of Ireland

Seamus McGuinness, Frances McGinnity, Philip O'Connell

'New' and 'Old' Social Risks: Life Cycle and Social Class Perspectives on Social Exclusion in Ireland

Christopher T. Whelan and Bertrand Maître

The Climate Preferences of I rish Tourists by Purpose of Travel

Seán Lyons, Karen Mayor and Richard S.J. Tol

A Hirsch Measure for the Quality of Research Supervision, and an Illustration with Trade Economists

Frances P. Ruane and Richard S.J. Tol

223 Environmental Accounts for the Republic of I reland: 1990-2005

Seán Lyons, Karen Mayor and Richard S.J. Tol

Assessing Vulnerability of Selected Sectors under Environmental Tax Reform: The issue of pricing power

J. Fitz Gerald, M. Keeney and S. Scott

221 Climate Policy Versus Development Aid Richard S.J. Tol

220 Exports and Productivity - Comparable Evidence for 14 Countries 
The International Study Group on Exports and Productivity

Energy-Using Appliances and Energy-Saving Features: Determinants of Ownership in I reland J oe O'Doherty, Seán Lyons and Richard S.J. Tol

The Public/Private Mix in Irish Acute Public Hospitals: Trends and Implications Jacqueline O'Reilly and Miriam M. Wiley

Regret About the Timing of First Sexual Intercourse: The Role of Age and Context Richard Layte, Hannah McGee

Determinants of Water Connection Type and Ownership of Water-Using Appliances in I reland J oe O'Doherty, Seán Lyons and Richard S.J. Tol

Unemployment - Stage or Stigma?

Being Unemployed During an Economic Boom Emer Smyth

The Value of Lost Load Richard S.J. Tol

Adolescents' Educational Attainment and School Experiences in Contemporary I reland

Merike Darmody, Selina McCoy, Emer Smyth

Acting Up or Opting Out? Truancy in Irish Secondary Schools

Merike Darmody, Emer Smyth and Selina McCoy

211 Where do MNEs Expand Production: Location Choices of the Pharmaceutical Industry in Europe after 1992

Frances $P$. Ruane, Xiaoheng Zhang

$210 \quad$ Holiday Destinations: Understanding the Travel Choices of Irish Tourists

Seán Lyons, Karen Mayor and Richard S.J. Tol

209 The Effectiveness of Competition Policy and the Price-Cost Margin: Evidence from Panel Data Patrick McCloughan, Seán Lyons and William Batt 
Tax Structure and Female Labour Market Participation: Evidence from I reland

Tim Callan, A. Van Soest, J.R. Walsh

207

Distributional Effects of Public Education Transfers in Seven European Countries

Tim Callan, Tim Smeeding and Panos Tsakloglou 